\title{
Parapharyngeal Neoplasm
}

National Cancer Institute

\section{Source}

National Cancer Institute. Parapharyngeal Neoplasm. NCI Thesaurus. Code C162820.

A benign or malignant neoplasm that affects the parapharyngeal space. 